\title{
Protein Flexibility and Ligand Rigidity: A Thermodynamic and Kinetic Study of ITAM- Based Ligand Binding to Syk Tandem SH2
}

\author{
Nico J. de Mol, ${ }^{*[a]}$ M. Isabel Catalina, ${ }^{[b, c]}$ Frank J. Dekker, ${ }^{[a, d]}$ Marcel J. E. Fischer, ${ }^{[a]}$ \\ Albert J. R. Heck, ${ }^{[b]}$ and Rob M. J. Liskamp ${ }^{[a]}$
}

\begin{abstract}
The Syk tandem Src homology 2 domain (Syk tSH2) constitutes a flexible protein module involved in the regulation of Syk kinase activity. The Syk $\mathrm{t} \mathrm{SH} 2$ domain is assumed to function by adapting the distance between its two SH2 domains upon bivalent binding to diphosphotyrosine ligands. A thermodynamic and kinetic analysis of ligand binding was performed by using surface plasmon resonance (SPR). Furthermore, the effect of binding on the Syk $\mathrm{tSH} 2$ structural dynamics was probed by hydrogen/deuterium exchange and electrospray mass spectrometry (ESI-MS). Two ligands were studied: 1, a flexible peptide derived from the $\mathrm{SSH}_{2}$ recognition ITAM sequence at the $\gamma$ chain of the FcERI-receptor, and 2, a ligand in which the amino acids between the two SH2 binding motifs in ligand 1 have been replaced by a rigid linker of comparable length. Both ligands display comparable affinity for
\end{abstract}

Syk tSH2 at $25^{\circ} \mathrm{C}$, yet a major difference in thermodynamics is observed. Upon binding of the rigid ligand, 2, the expected entropy advantage is not realized. On the contrary, 2 binds with a considerably higher entropy price of $\sim 9 \mathrm{kcal} \mathrm{mol}^{-1}$, which is attributed to a further decrease in protein flexibility upon binding to this rigid ligand. The significant reduction in deuterium incorporation in the Syk $\mathrm{tSH} 2$ protein upon binding of either 1 or 2, as monitored by ESI-MS, indicates a major reduction in protein dynamics upon binding. The results are consistent with a two-step binding model: after an initial binding step, a rapid structural change of the protein occurs, followed by a second binding step. Such a bivalent binding model allows high affinity and fast dissociation kinetics, which are very important in transient signaltransduction processes.

\section{Introduction}

Protein phosphorylation functions as an on/off switch in intracellular molecular signal transduction. In the recognition of protein sequences containing phosphotyrosine (pY), Src homology 2 ( $\mathrm{SH} 2$ ) domains play a crucial role. $\mathrm{SH} 2$ domains are protein modules of approximately 100 amino acid residues, occurring in a wide variety of signaling proteins. The structural basis of the recognition of specific sequences by $\mathrm{SH} 2$ domains has been elucidated by X-ray crystallography and NMR ${ }^{[1]}$ Individual $\mathrm{SH} 2$ domains bind to specific tyrosine-phosphorylated sequences with dissociation constants ranging from 200 to $1000 \mathrm{nM}^{[2]} \mathrm{SH} 2$ domains are present in tandem in a number of signaling proteins, including ZAP-70, Syk, PI-3 kinase, SHP-2, and PLC- $\gamma$. The affinities of bivalent interactions with tandem $\mathrm{SH} 2$ domains are much higher than those for binding to single $\mathrm{SH} 2$ domains, being found in the $0.5-50 \mathrm{~nm}$ range. Similarly, the specificities of interactions with tandem- $\mathrm{SH} 2$ ( $\mathrm{tSH} 2)$ domains are also much greater than those of single $\mathrm{SH} 2$ domains. $^{[2]}$

Spleen tyrosine kinase (Syk) contains two $\mathrm{SH} 2$ domains in tandem, in addition to its kinase domain. This kinase plays a crucial role in the signal transduction of certain members of the family of multichain immune recognition receptors, such as the high-affinity receptor for $\operatorname{lgE}(\mathrm{Fc \varepsilon RI})$ and the B cell antigen receptor $(B C R){ }^{[3]}$ Stimulation of FceRl induces the onset of IgE-mediated allergic reactions through the release of several proinflammatory mediators from mast cells and basophils. ${ }^{[4]}$ Early events in the FceRI-mediated signaling are tyrosine phosphorylation of the FceRl $\beta$ - and $\gamma$-subunits by the Src family kinase Lyn and activation of the Syk/Zap family kinase Syk. ${ }^{[5]}$ The $\beta$ - and $\gamma$-subunits of FceRI each contain a so-called immunoreceptor tyrosine-based activation motif (ITAM). The consensus sequence for ITAMs is $\mathrm{YXX}(\mathrm{I} / \mathrm{L})-(\mathrm{X})_{6-8}-\mathrm{YXX}(\mathrm{I} / \mathrm{L})$, in which $\mathrm{X}$ can be any amino acid. ITAM sequences are bivalent docking

[a] Dr. N. J. de Mol, Dr. F. J. Dekker, Dr. M. J. E. Fischer, Prof. Dr. R. M. J. Liskamp Department of Medicinal Chemistry

Utrecht Institute for Pharmaceutical Sciences

Utrecht University (UIPS)

Sorbonnelaan 16, 3584 CA Utrecht (The Netherlands)

Fax: $(+31)$ 30-253-6655

E-mail:n.j.demol@pharm.uu.nl

[b] Dr. M. I. Catalina, Prof. Dr. A. J. R. Heck Department of Biomolecular Mass Spectrometry UIPS and Bijvoet Center for Molecular Sciences Sorbonnelaan 16, 3584 CA Utrecht (The Netherlands)

[c] Dr. M. I. Catalina

Current address:

Department of Parasitology, Leiden University Medical Center (LUMC) Albinusdreef 2, 2333ZA Leiden

[d] Dr. F. J. Dekker

Current address:

Max Planck Institute for Molecular Physiology

Otto-Hahn-Straße 11, 44227 Dortmund (Germany) 
sites for Syk or ZAP-70 $\mathrm{tSH} 2$ if both tyrosines are phosphorylated. A Syk mutant, lacking $\mathrm{tSH} 2$, is constitutively active, ${ }^{[6]}$ showing the importance of $\mathrm{tSH} 2$ for regulation of the Syk kinase activity. The mechanism of Syk activity regulation is not yet known in full detail. Upon docking of Syk $\mathrm{tSH} 2$ on the ITAM of the FceRI $\gamma$-subunit, Syk becomes phosphorylated on tyrosines 519 and 520 in its activation loop, mainly through Syk transphosphorylation. ${ }^{[7]}$ However, in contrast to many other kinases, this phosphorylation of the activation loop is not necessary for Syk activation. ${ }^{[8]}$ Furthermore, a unique insert in the linker between $\mathrm{tSH} 2$ and the kinase domain is necessary for the functioning of Syk in immunoreceptor signaling, and this insert can regulate the ability of Syk to bind ITAMs. ${ }^{[9]}$

An allosteric change induced in $\mathrm{tSH}_{2}$ upon binding of an ITAM sequence may be involved in the regulation of Syk activity. ${ }^{[6,10]}$ This is supported by the structures of $\mathrm{tSH} 2$ in the bound and the free states of the other member of the Syk/ZAP family kinases: ZAP-70. ${ }^{[11,12]}$ In the unbound state, the two SH2 domains of ZAP-70 are far apart from each other. Upon ITAM binding, the $\mathrm{tSH} 2$ of ZAP-70 undergoes a large conformational change, becoming locked in a more "closed" conformation. ${ }^{[12]}$ For Syk tSH2 only the crystal structure of its bound form with a doubly phosphorylated ITAM is available (Figure 1). The

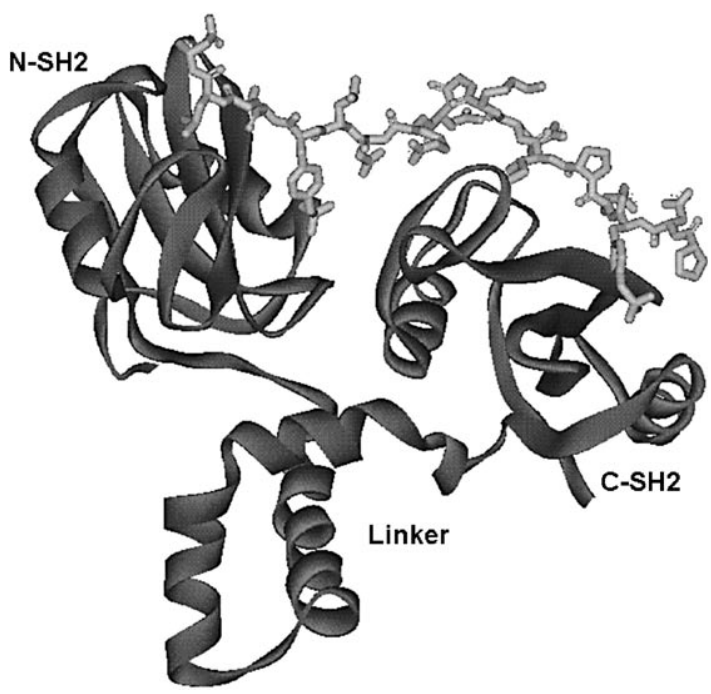

Figure 1. X-ray structure of Syk tandem SH2 domain (ribbon) with doubly phosphorylated ITAM from the T cell receptor CD $3 \varepsilon$ chain (sticks). The protein consists of two $\mathrm{SH} 2$ domains connected by a flexible linker. PDB entry $1 \mathrm{~A} 81 .{ }^{[13]}$

asymmetric unit contains six copies of the bound $\mathrm{tSH} 2$ with variable distances between the $\mathrm{pY}$ binding sites of the $\mathrm{SH} 2$ domains, indicating that a certain degree of flexibility also exists in the bound state. ${ }^{[13]} \mathrm{A}$ role for the inter-SH2 distance can also be inferred from the flexible structure of the helical coiled coil linker between the two SH2 domains. ${ }^{[13,14]}$ Furthermore, tyrosine 130 in the inter-SH2 linker of Syk tSH2 plays a crucial role in binding to the $\mathrm{B}$ cell antigen receptor and receptor activation. ${ }^{[15]}$
In view of the high specificity and affinity of bivalent ligands for $\mathrm{tSH} 2$, the development of inhibitors of Syk kinase activation would be a very attractive strategy for the treatment of allergic diseases such as asthma ${ }^{[16-18]}$ and of breast cancer. ${ }^{[3]}$ Our group has been working on ITAM-based peptidomimetics. ${ }^{[19-21]}$ The intervening seven amino acids between the $\mathrm{SH} 2$ binding motifs pYTGL and pYETL of the ITAM of the FCERI $\gamma$-chain $(\gamma$ ITAM) were replaced by non-peptidic flexible and rigid linkers. ${ }^{[20,21]}$ This yields ligands with high affinity, approaching that of the native ITAM peptide. This is in accordance with the $X$ ray structures, which indicate that the intervening amino acids do not contribute significantly to binding. ${ }^{[13]}$

We were most intrigued, however, by the fact that rigidization of the linker between the $\mathrm{SH} 2$ binding motifs in the ITAM sequence did not yield an affinity higher than that of the flexible native peptide. ${ }^{[21]}$ Ideally, rigidization of ligands in multivalent interactions should reduce the entropy costs of binding, ${ }^{[22]}$ so we primarily asked ourselves: why does the assumed entropy gain with a rigid ligand not yield binding stronger than that of the parent diphosphorylated peptide, and is design of rigid ITAM mimetics a fruitful strategy? To address this issue, we performed a thermodynamic study of Syk $\mathrm{tSH} 2$ binding to a flexible $\gamma$-ITAM peptide and a rigid ITAM mimetic, using surface plasmon resonance (SPR). The SPR experiments also allowed a kinetic analysis to be performed and the binding mode to be studied in more detail. Furthermore, to evaluate the effects of ligand binding on the overall Syk $\mathrm{tSH} 2$ protein dynamics, hydrogen/deuterium exchange was monitored by electrospray mass spectrometry (ESI-MS). As well as an explanation as how the Syk tSH2 flexibility hampers stronger binding of rigid linkers, the kinetics also give insight into how high affinity combines with fast on- and off-rates.

\section{Results}

\section{Thermodynamic analysis of a flexible and rigid ligand binding to Syk $\mathrm{tSH} 2$}

The two FceRI $\gamma$-ITAM-derived compounds used in this study are shown. Compound $\mathbf{1}$ is the all-peptide ITAM sequence pYTGL-NTRSQET-pYETL, and compound $\mathbf{2}$ is a peptidomimetic in which the seven amino acids between the two $\mathrm{SH} 2$ binding motifs PYTGL and PYETL have been replaced by a rigid propynylbenzoyl linker. From molecular modeling it appears that this linker is of approximately the same length as the averaged length of the amino acid linker in the $\mathrm{X}$-ray structures of Syk tSH2. ${ }^{[21]}$

In our SPR assay the affinity constant for interaction in solution $\left(K_{\mathrm{s}}\right)$ was derived from ligand competition experiments. ${ }^{[23]}$ The all-peptide $\gamma$-ITAM 1, extended with a hexanoyl spacer, was immobilized on the sensor chip surface. SPR assays were performed over a temperature range from 10 to $40^{\circ} \mathrm{C}$. As shown in Figure $2 \mathrm{a}$, the equilibrium SPR signal versus the $\mathrm{tSH} 2$ concentration can be fitted to a one-site binding Langmuir isotherm [Eq. (3); Experimental Section], yielding $K_{c}$, the affinity for the interaction at the sensor chip, and the maximum binding capacity $\left(R_{\max }\right)$. Examples of ligand competition experi- 


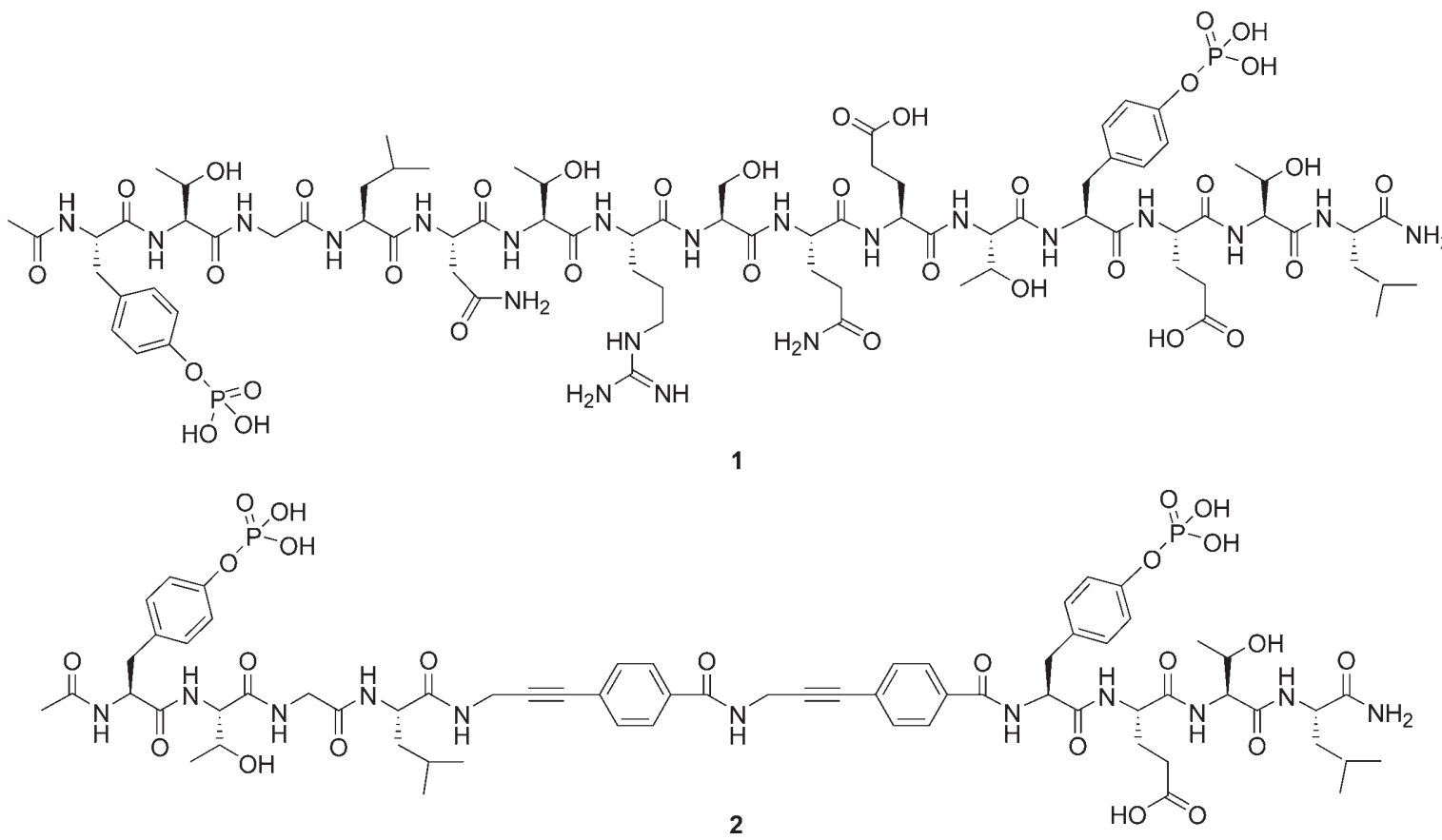

ments to obtain the affinity constant in solution are shown in Figure $2 \mathrm{~b}$. The obtained affinity constants at different temperatures are shown in a van't Hoff plot in Figure 3 ; the $K_{\mathrm{D}}$ values ranged from 2.9 to $12 \mathrm{nм}$ for the flexible ligand 1 and from 3.3 to 40 пм for the rigid ligand 2 .

Figure 3 shows that the $K_{\mathrm{C}}$ and $K_{\mathrm{S}}$ values for binding to the $\gamma$-ITAM 1 are identical, so the affinity is not influenced by immobilization of the peptide on the SPR sensor chip. The van't Hoff plot for the rigid ligand $\mathbf{2}$ is significantly different from that for ligand 1 . The data have been fitted according to the integrated van't Hoff equation [Eq. (4); Experimental Section], and the thermodynamic parameters derived from the fits are included in Table 1. At $25^{\circ} \mathrm{C}$, the free binding energy $\left(\Delta G^{0}\right)$ values for the flexible and the rigid ligand are rather similar, but the entropy contribution to $\Delta G^{0}$ is $\sim 9 \mathrm{kcal} \mathrm{mol}^{-1}$ less for rigid ligand 2, which is completely compensated by the enthalpy contribution. For both ligands $\Delta C_{p}$ is close to zero, resulting in practically linear van't Hoff curves.

The observed affinity at $25^{\circ} \mathrm{C}\left(K_{\mathrm{D}}\right.$ is $\left.5 \mathrm{~nm}\right)$ compares well with previous reports based on alternative techniques. ${ }^{[24,25]}$ Grucza et al. ${ }^{[26]}$ determined binding at different temperatures by fluorescence titration and found a somewhat lower affinity for an ITAM peptide derived from the CD3E-chain of the Tcell receptor $\left(35 \mathrm{~nm}\right.$ at $\left.25^{\circ} \mathrm{C}\right)$. We performed a van't Hoff analysis of the Grucza data and the outcome compares very well with our results, especially with respect to the $\Delta H^{0}$ and $\Delta C_{\mathrm{p}}$ values (Table 1).

\section{Kinetic analysis of flexible and rigid ligand binding to Syk tSH2}

The time-related information of the SPR signal allows kinetic analysis of the binding process and transition state analysis. In principle, $k_{\text {off }}$ could be derived from the dissociation phase of the sensorgram: that is, after removal of the protein. In practice, however, the dissociation phase is frequently influenced by transport limitation and rebinding (see below). We therefore mea- 
Table 1. Thermodynamic parameters for binding of all-peptide FcerRI $\gamma$ ITAM (1) and a rigid ITAM-mimetic (2) to Syk tandem SH2 domain in HBS buffer $\mathrm{pH}$ 7.4. Values \pm standard error as derived from fits of data in Figure 3 with Equation (4). For comparison, parameters derived by us from fluorescence data for binding of $\varepsilon$-ITAM (Ac-PDPYEPIRKGQRDLpYSGLNQR-NH $\mathrm{N}_{2}$ ) are also included.

\begin{tabular}{|lccc|} 
& Compound 1 & & \\
& Compound 2 & $\varepsilon^{\text {b] }}$ & ITAM $^{[\mathrm{d}]}$ \\
\hline$\Delta H^{0}\left[\mathrm{kcal} \mathrm{mol}^{-1}\right]^{[\mathrm{a}]}$ & $-10.3 \pm 0.8$ & $-19.2 \pm 1.6$ & $-10.9 \pm 3.2$ \\
$T \Delta S^{0}\left[\mathrm{kcal} \mathrm{mol}^{-1}\right]^{[\mathrm{a}]}$ & $0.9 \pm 0.8$ & $-8.4 \pm 1.6$ & $-1.0 \pm 3.2$ \\
$\Delta C_{\mathrm{p}}\left[\mathrm{cal} \mathrm{mol}^{-1} \mathrm{~K}^{-1}\right]$ & $-140 \pm 200$ & $60 \pm 420$ & $-240 \pm 350$ \\
$\Delta G^{0}\left[\mathrm{kcal} \mathrm{mol}^{-1}\right]^{\mathrm{a}, \mathrm{c}]}$ & -11.2 & -10.8 & -9.9 \\
$K_{\mathrm{D}}[\mathrm{nm}]^{[\mathrm{a}]}$ & 5.6 & 11.6 & 35
\end{tabular}

[a] At reference temperature $25^{\circ} \mathrm{C}$. [b] From combined $K_{\mathrm{C}}$ and $K_{\mathrm{S}}$ values. [c] Calculated from $\Delta G^{0}=\Delta H^{0}-T \Delta S^{0}$. [d] From fluorescence data. ${ }^{[26]}$

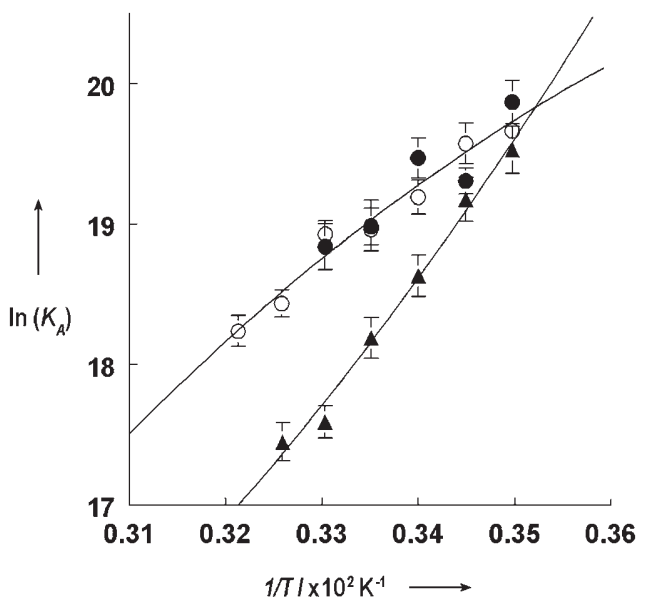

Figure 3. van't Hoff plot for binding of 1 and 2 to Syk tandem SH2. Affinity for immobilized $\gamma$-ITAM-peptide (1) $K_{\mathrm{C}}(O)$; affinity for $\gamma$-ITAM (1) in solution $K_{\mathrm{S}}(\bullet)$. Affinity of ITAM-mimetic with rigid linker (2) in solution $K_{\mathrm{S}}(\mathbf{\Delta})$. Experiments in HBS buffer $\mathrm{pH}$ 7.4. The bars indicate the standard error in the affinity data, and the lines are the fits according to the integrated van't Hoff equation [Eq. (4)].

sured dissociation after addition of competing ligand 1 to avoid effects of rebinding of released protein.

In order to establish how much peptide was needed to avoid the influence of rebinding completely, experiments were performed with increasing amounts of ligand 1. A relatively large amount of competing peptide is needed (Figure 4). At $0.22 \mathrm{~mm}$, the maximum dissociation rate $\left(k_{\text {off }}\right)$ is reached and the dissociation phase can be fitted with a monoexponential fit [Eq. (6); Experimental Section]. Dissociation experiments in the presence of $0.22 \mathrm{~mm}$ peptide were performed over a temperature range from 10 to $30^{\circ} \mathrm{C}$. At temperatures higher than $30^{\circ} \mathrm{C}$ the results were less reliable, because the dissociation becomes very rapid and also because small temperature effects at short time intervals after addition of the peptide disturbed the SPR signal. The $k_{\text {off }}$ values at temperatures $>30^{\circ} \mathrm{C}$ were obtained from extrapolation of the linear Arrhenius plot. Dissociation experiments with a monovalent Syk $\mathrm{tSH} 2$ binding peptide (Ac-pYETL- $\mathrm{NH}_{2}$ ) gave comparable results (not shown).

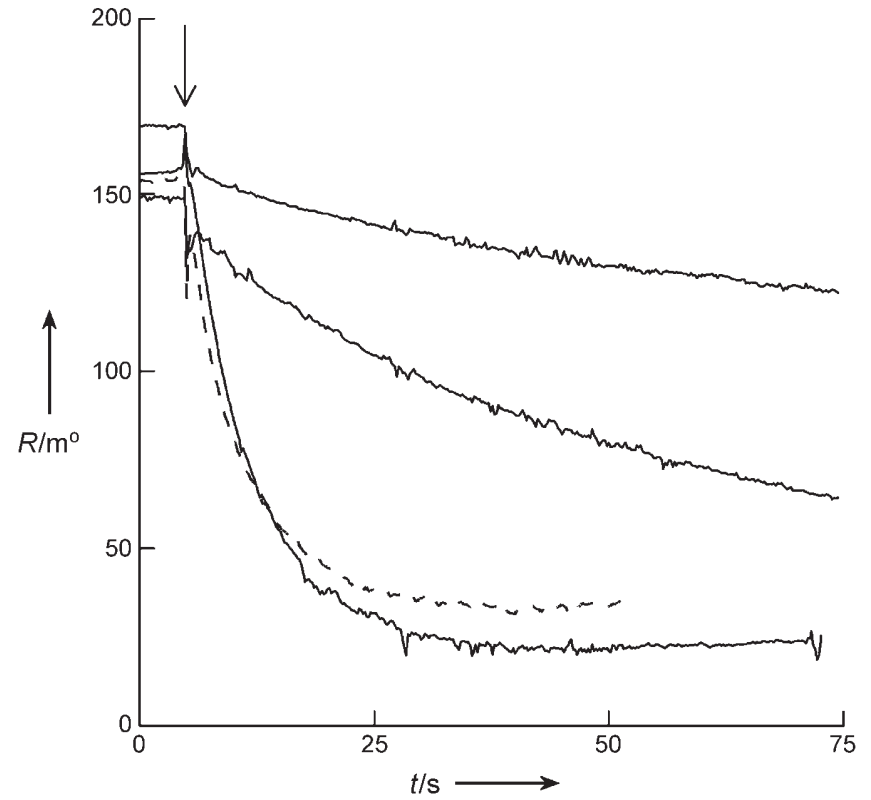

Figure 4. Dissociation rate of Syk tandem $\mathrm{SH} 2$ domain from immobilized $\gamma$-ITAM after addition of $\gamma$-ITAM peptide at $20^{\circ} \mathrm{C}$. Syk tSH2 (100 nM) has reached equilibrium binding before addition of peptide (see arrow). Solid traces: (with increasing dissociation rate) $2.22 \times 10^{-6} ; 2.22 \times 10^{-5} ; 2.22 \times 10^{-4} \mathrm{M}$ $\gamma$-ITAM peptide, respectively. Dashed trace: $3.64 \times 10^{-4} \mathrm{M} \gamma$-ITAM.

Dissociation of the tandem $\mathrm{SH} 2$ domain is rapid, as has also been observed for single $\mathrm{SH} 2$ proteins. ${ }^{[27]}$ At $25^{\circ} \mathrm{C}$, the observed $k_{\text {off }}$ value is $0.18 \mathrm{~s}^{-1}$, between reported values of $0.01 \mathrm{~s}^{-1}$ and $0.7 \mathrm{~s}^{-1}$ for dissociation of Syk tSH2 from diphosphorylated ITAM, and very close to a value of $0.13 \mathrm{~s}^{-1}$ used in a mathematical model of the kinetics of early FceRI-related phosphorylation. ${ }^{[28]}$

With $K_{\mathrm{D}}$ and $k_{\text {off }}$ known, the association rate $\left(k_{\text {on }}\right)$ can be calculated $\left(k_{\text {on }}\right.$ is $\left.k_{\text {off }} / K_{\mathrm{D}}\right)$. By using this approach, $k_{\text {on }}$ was determined to be $3.2 \times 10^{7} \mathrm{M}^{-1} \mathrm{~s}^{-1}$ at $25^{\circ} \mathrm{C}$, which compares fairly well with the value of $2.1 \times 10^{7} \mathrm{M}^{-1} \mathrm{~s}^{-1}$ obtained for the $\varepsilon$-ITAM by stopped-flow fluorescence. ${ }^{[26]}$ The temperature dependencies of $k_{\text {on }}$ and $k_{\text {off }}$ are shown in Figure 5 as Eyring plots. The dissociation data were fitted with a linear relationship [Eq. (5); Experimental Section] and the nonlinear association data with Equation (4). ${ }^{[29]}$

The activation parameters derived from the fits are included in Table 2. Enthalpy and entropy appear to contribute almost equally to formation of the transition state for binding of the flexible ligand 1 to $\mathrm{tSH} 2$. On going from the transition state to the bound state there is a considerable enthalpy contribution to the change in free energy. As the thermodynamic data are compatible with a further decrease in protein flexibility upon binding, especially of the rigid ligand 2, we looked for a more direct confirmation by probing the effects of binding to $\mathrm{tSH} 2$ protein on hydrogen/deuterium (H/D) exchange and electrospray mass spectra (ESI-MS). 

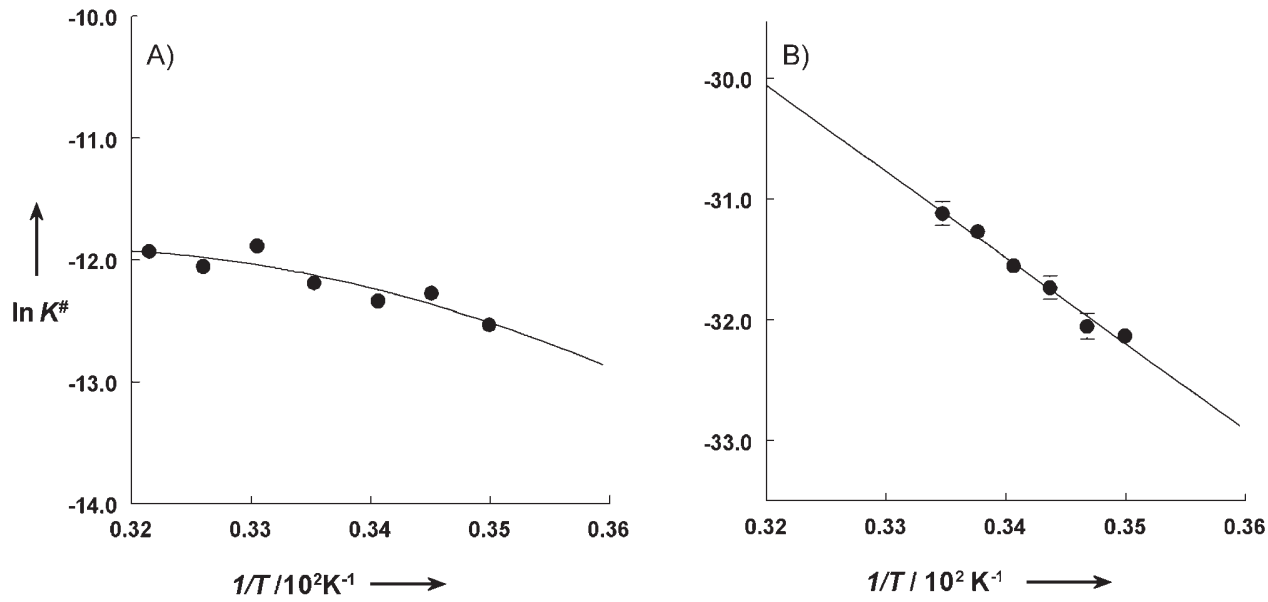

Figure 5. Eyring plots for Syk tandem SH2 domain interacting with immobilized $\gamma$-ITAM-peptide (1). $K^{\neq}$is $k \cdot h / k_{\mathrm{B}} . T$, in which the rate constant $k$ is $k_{\text {on }}$ (panel a), or $k_{\text {off }}$ (panel b). $k_{\text {off }}$ has been assayed from SPR dissociation experiments in the presence of $2.2 \times 10^{-4} \mathrm{M} \gamma$-ITAM peptide. The association rate is calculated from $k_{\text {on }}=K_{\mathrm{A}} k_{\text {off. }}$ Fit in a is with Equation (4), and in b with Equation (5).

Table 2. Parameters for activation to the transition state for binding of FcERI $\gamma$-ITAM to Syk tandem SH2. The activation parameters \pm standard error are derived from the Eyring plots in Figure 5.

\begin{tabular}{|lcc|} 
Activation parameter & Association $^{[\mathrm{cc}]}$ & Dissociation $^{[\mathrm{b}]}$ \\
\hline$\Delta H^{+}\left[\mathrm{kcal} \mathrm{mol}^{-1}\right]^{[\mathrm{a}]}$ & $4.0 \pm 0.8$ & $14.2 \pm 0.9$ \\
$T \Delta S^{\mp}\left[\mathrm{kcal} \mathrm{mol}^{-1}\right]^{[\mathrm{a}]}$ & $-3.2 \pm 0.9$ & $-4.3 \pm 0.9$ \\
$\Delta C_{p}^{\neq}\left[\mathrm{cal} \mathrm{mol}^{-1} \mathrm{~K}^{-1}\right]$ & $-200 \pm 250$ & 0 \\
$\Delta G^{+}\left[\mathrm{kcal} \mathrm{mol}^{-1}\right]^{[\mathrm{a}, \mathrm{d}]}$ & 7.2 & 18.5 \\
\hline
\end{tabular}

[a] At reference temperature $25^{\circ} \mathrm{C}$. [b] Calculated from fit with Equation (5). [c] Calculated from fit with Equation (4). [d] Calculated from $\Delta G^{\neq}=\Delta H^{\neq}-T \Delta S^{\neq}$.

\section{Changes in the structural dynamics of the Syk tSH2 protein upon ITAM binding}

H/D exchange and ESI-MS: H/D exchange is a highly sensitive way of probing changes in structure and dynamics accompanying ligand binding, protein-protein interactions, and protein folding. ${ }^{[30,31]}$ In a recent study we reported a remarkable reduction in deuterium incorporation of the Syk $\mathrm{tSH} 2$ protein upon binding to the flexible native peptide $1 .^{[14]}$ Typical electrospray ionization mass spectra of the deuterated Syk $\mathrm{tSH} 2$, either ligand-free or bound to the rigid ligand 2, are shown in Figure $6 \mathrm{~A}$ and $6 \mathrm{~B}$. The spectrum of ligand-free Syk $\mathrm{tSH} 2$ shows a bimodal charge envelope: the more abundant charge envelope is centered around the 12-fold protonated protein ions, whereas the less intense envelope is localized around the $21+$ protein ions (Figure $6 \mathrm{~A}$ ). In contrast, the ESI spectrum of Syk $\mathrm{tSH}_{2}$ in the presence of rigid ligand $\mathbf{2}$ shows only a single charge envelope distribution with three markedly intense ions around the $12+$ ions of the protein-ligand complex.

The H/D-exchange kinetics of bound and unbound Syk $\mathrm{tSH}_{2}$ were followed by incubation in an ammonium acetate $\mathrm{D}_{2} \mathrm{O}$ solution ( $65 \mathrm{~mm}$, equivalent to neutral pD) with continuous monitoring of the increase in protein mass in the ESI mass spectrum. The total number of exchangeable hydrogens in the pro-

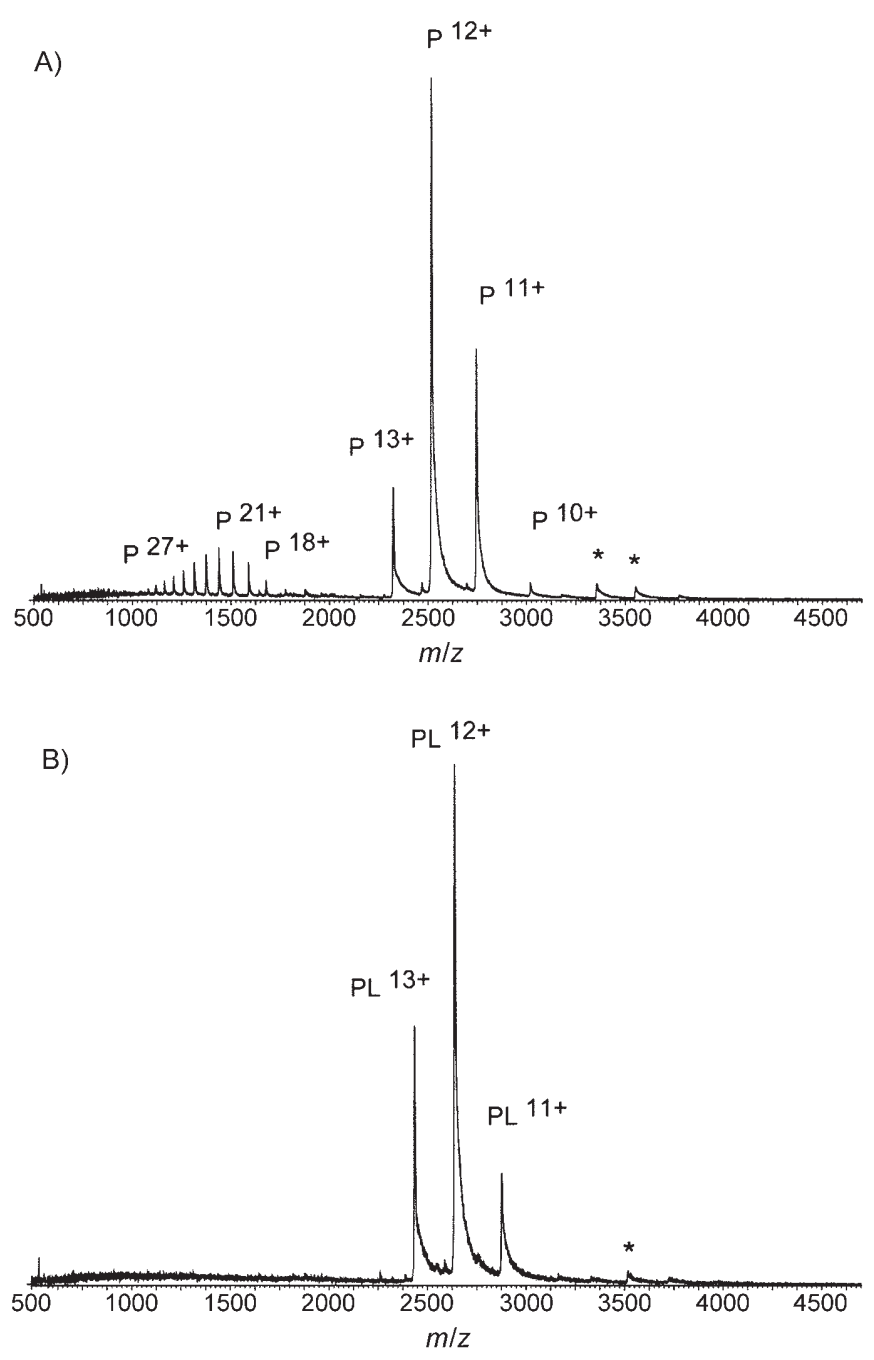

tein, as calculated from its amino acid sequence, is 490 . The noncovalent complexes of Syk tSH2 with its ligands are easily preserved in the gas phase in the mass spectrometer, as revealed by the spectrum shown in Figure 6B. However, to measure the deuterium uptake in the protein, the noncovalent complex was dissociated in the gas phase by application of a high cone voltage in the source interface, through which we monitored the mass of the released protein as described previously. ${ }^{[14]}$

\section{P 12}

Figure 6. ESI mass spectra of Syk $\mathrm{tSH} 2$ in a $\mathrm{D}_{2} \mathrm{O}$ solution (95\%) containing ammonium acetate at a concentration of $65 \mathrm{~mm}$ (neutral pD) after $25 \mathrm{~min}$ incubation: A) as ligand-free protein, B) in complexation with the rigid ITAM 2 $(1: 1)$ at a cone voltage of $190 \mathrm{~V}$. " $\mathrm{P}$ " stands for protein, and "PL" for the protein-peptide ligand complex. The numbers of charges on the ions are indicated in superscript. The asterisks denote small ion signals representing protein dimer ions. 
The deuterium uptake of the protein over time is displayed in Figure 7. The deuterium incorporation appears to be very rapid: within $1 \mathrm{~min}$ over $80 \%$ of the available protons have

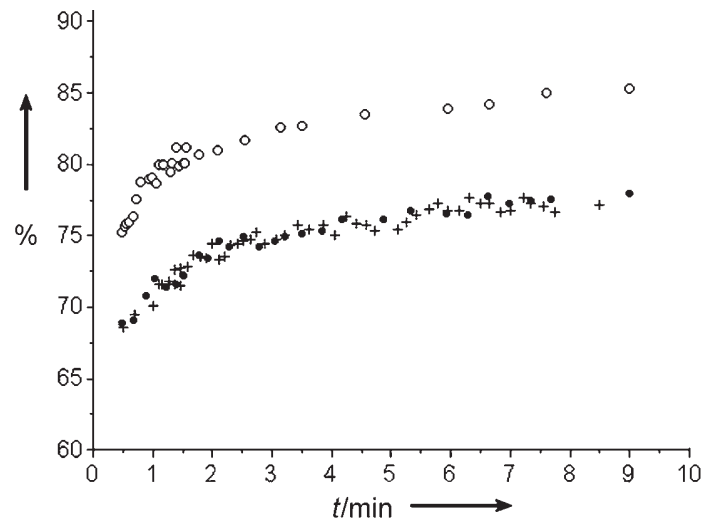

Figure 7. Percentage of Syk $\mathrm{tSH} 2$ deuteration vs. time upon $\mathrm{H} / \mathrm{D}$ exchange. The protein was exposed to buffered $\mathrm{D}_{2} \mathrm{O}$, both as the peptide ligand-free protein $(\circ)$ and in complexation with the flexible ITAM $(\bullet)$ and the rigid ITAM peptide (+). The maximum mass deviation errors fall around $\pm 3 \mathrm{Da}$ ( $\pm 1 \%$ protein deuteration).

been exchanged in the ligand-free protein and some $72 \%$ in the ligand-bound protein. From the curves, it is apparent that ligand binding has a remarkable effect on deuterium incorporation, diminishing it quite dramatically overall, but no difference in effect between the flexible and the rigid ligand was observed.

\section{Evaluation of binding models by SPR real-time association kinetics}

The kinetic information in the time-dependent SPR signal allows evaluation of predefined binding models. For this, Morton and Myszka have developed the computer program CLAMP. $^{[32]}$ In a global analysis, this program fits the SPR curves from several protein concentrations simultaneously, returning the kinetic parameters of the binding model. Changes in H/D exchange have been associated with conformational changes, ${ }^{[14,33-35]}$ and this inspired us to examine a two-step model with an initial binding event followed by a structural change of the complex from $A B 1$ to $A B 2$ (model 2, Scheme 1). Together with this, a simple bimolecular model in which the protein-ligand structural change is absent was evaluated (model 1, Scheme 1). A transport step was also included in both binding models, to allow for the rate-limiting diffusion of the protein from the bulk solution to the sensor surface, which appears from the observed rebinding during dissociation (Figure 4). ${ }^{[27,36]}$

Figure 8 shows sensorgrams of the association phase at 11 and $35^{\circ} \mathrm{C}$. The data have been fitted to the binding models shown in Scheme 1. In the fits, $R_{\max }$ and $k_{\text {off }}$ have been kept to experimentally determined values, obtained as described above. It appears that the bimolecular model 1 is not able to
1. Transport bimolecular model

$$
\begin{aligned}
& A_{\text {bulk }} \underset{k_{\text {tr }}}{\stackrel{k_{\text {tr }}}{\rightleftharpoons}} A_{\text {sensor }} \\
& A_{\text {sensor }}+B \stackrel{k_{\text {on }}}{\rightleftharpoons} A B
\end{aligned}
$$

2. Transport two-step mode

$$
\begin{aligned}
& A_{\text {bulk }} \frac{k_{\text {tr }}}{k_{\text {tr }}} A_{\text {sensor }} \\
& A_{\text {sensor }}+B \stackrel{k_{\text {on }}}{\rightleftharpoons} A B 1 \\
& A B 1 \stackrel{k_{\text {off }}}{\underset{k_{\text {conf }}}{\rightleftharpoons}} A B 2
\end{aligned}
$$

Scheme 1. Binding models evaluated by global analysis with CLAMP. Species A denotes unbound Syk tandem SH2, B denotes the $\gamma$-ITAM peptide 1, and $A B$ represents ITAM-Syk $\mathrm{tSH} 2$ complexes in various forms.

fit the curves at low temperatures in all detail (Figure $8 \mathrm{a}$ ); in particular, the slower association after the initial rapid increase is not well reproduced. On the other hand, the two-step model 2 is able to fit the experimental curves well (Figure $8 \mathrm{~b}$ ). Interestingly, at higher temperatures $\left(>30^{\circ} \mathrm{C}\right)$ model 1 also describes the experimental curves adequately, indicating that the $A B 1$ to $A B 2$ change becomes so fast that it can no longer be kinetically resolved from the initial association step (Figure $8 \mathrm{c}$ ).

For model 2 the equilibrium signal $\left(R_{\text {eq }}\right)$ versus the protein concentration can also be described by a one-site binding Langmuir isotherm as shown in Figure $2 \mathrm{a}$. Here, the derived $K_{\text {obs }}$ value is an apparent binding constant, containing contributions both from the initial binding step and from the structure change: $K_{\mathrm{b}}$ and $K_{\text {conf }}$ respectively [see Equation ( $1 \mathrm{~d}$ ); Theory Section]. By use of the Monte Carlo function of CLAMP, the kinetic parameters of model 2 have been obtained from repeated fits through the use of various starting values (see Experimental Section). The equilibrium constants $K_{\mathrm{b}}$ and $K_{\text {conf }}$ contributing to $K_{\mathrm{obs}}$ derived from the kinetic parameters at 11 and $25^{\circ} \mathrm{C}$, appeared to be highly consistent and are given in Table 3. The high value of $K_{\text {conf }}$ (Table 3 ) indicates that at completion of the binding process the equilibrium is almost completely shifted to the $A B 2$ form of the complex. As appears from Table 3, the temperature especially seems to affect the initial binding step, with only a modest effect on $K_{\text {conf }}$.

\section{Discussion}

Kinetic and thermodynamic information on protein-protein interactions gives insight into the nature of the binding process and assists our understanding of the function of intermolecular interactions, thereby guiding rational drug design. Here we characterize the binding of a flexible diphosphorylated ITAM peptide and a rigid ITAM-derived ligand to the Syk tSH2 domain by thermodynamic and kinetic analysis by SPR, as well as by studying effects on protein dynamics with ESI-MS. From previous work by us and by others it appeared that such an SPR approach can give reliable thermodynamic data. ${ }^{[37,38]}$

The affinity of Syk tSH2 for $\gamma$-ITAM in solution was found to be identical to that for immobilized $\gamma$-ITAM (1) at the SPR sensor surface. This has been observed previously for single $\mathrm{SH} 2$ domains, ${ }^{[38]}$ and indicates that the affinity is not influenced by additional effects of the sensor chip. Comparison of the thermodynamic binding parameters of the flexible native peptide 1 with those of the rigid ligand 2 (Figure 3, Table 1) shows 

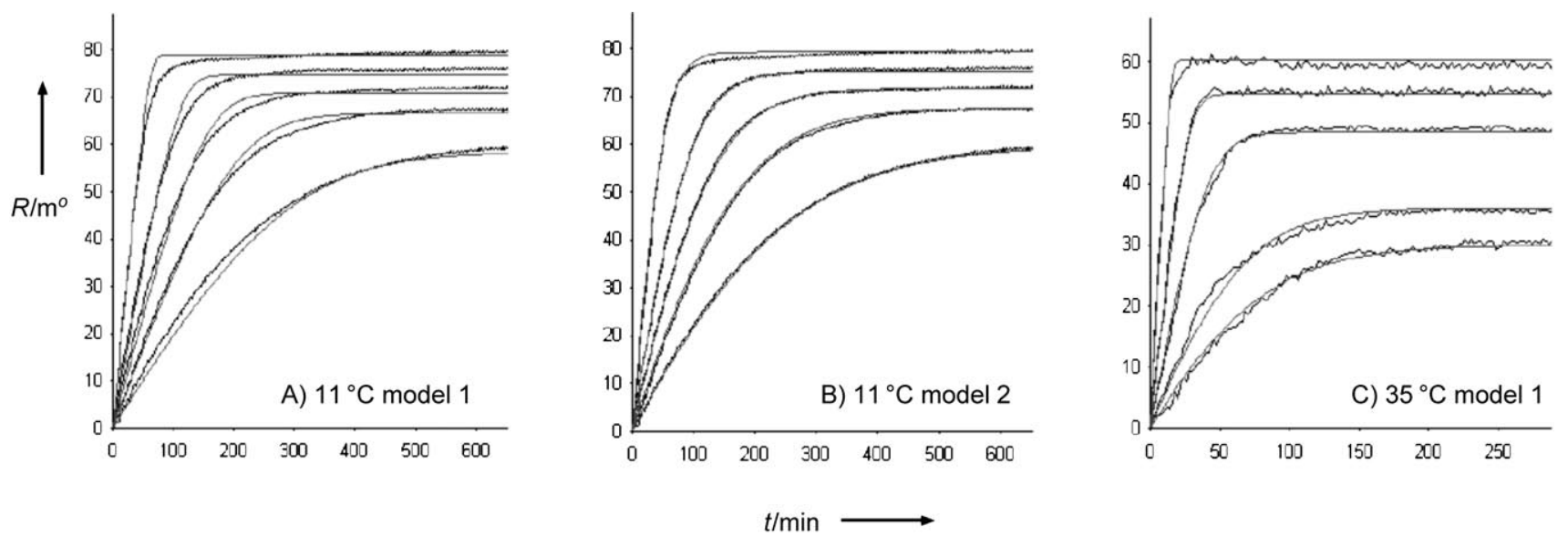

Figure 8. SPR sensorgrams (SPR signal R vs. time) of the association phase of FcERI $\gamma$-ITAM (1) binding to Syk tandem SH2 in HBS buffer pH 7.4 , at 11 (a and b) and $35^{\circ} \mathrm{C}$ (c). The data have been fitted by use of the CLAMP program (thin lines), according to the indicated models (see also Scheme 1).

Table 3. Equilibrium constants derived from kinetic analysis of sensorgrams of FceRI $\gamma$-ITAM binding to Syk tandem $\mathrm{SH} 2$, with the two-step model (model 2, Scheme 1).

\begin{tabular}{lll|} 
Equilibrium constants & $11^{\circ} \mathrm{C}$ & $25^{\circ} \mathrm{C}$ \\
\hline Initial binding step $K_{\mathrm{b}}{ }^{[a]}\left[\mathrm{M}^{-1}\right]$ & $1.89( \pm 0.02) \times 10^{7}$ & $1.04( \pm 0.02) \times 10^{7}$ \\
Conformation change $K_{\text {conf }}{ }^{[b]}$ & $18.0 \pm 0.5$ & $14.7 \pm 0.3$ \\
$K_{\mathrm{D}, \mathrm{obs}}{ }^{[\mathrm{c}]}[\mathrm{nm}]$ & 2.8 & 6.1 \\
\hline
\end{tabular}

[a] Calculated from $k_{\text {on }} / k_{\text {off }}$ (see Scheme 1$) .[\mathrm{b}][A B 2] /[A B 1]$ is calculated from $k_{\text {conf }} / k_{- \text {conf }}$ (see Scheme 1). [c] Calculated from Equation (1), with $K_{\mathrm{D}, \mathrm{obs}}=1 / K_{\mathrm{obs}}$.

a remarkable difference in binding energetics, the comparable affinities notwithstanding. Binding of ligand 1 to Syk $\mathrm{tSH}_{2}$ is almost completely enthalpy-driven (Table 1). Furthermore, formation of the transition state for this interaction has modest entropy costs of approximately $3-4 \mathrm{kcal} \mathrm{mol}^{-1}$ (Table 2). Rigidization is frequently used in nature and in drug design, to obtain a more favorable entropy contribution. In this case, however, the opposite is observed: binding of the rigid ligand 2 has a higher entropy cost, of approximately $9 \mathrm{kcal} \mathrm{mol}^{-1}$, than binding of the flexible ligand 1 to the $\mathrm{tSH} 2$ domain, which is completely compensated by gain in enthalpy. The intervening amino acids in the ITAM sequence hardly contribute to binding, ${ }^{[13]}$ and the rigid linker has also been shown to make no contribution to binding. ${ }^{[21]}$ The thermodynamic results agree with a much higher degree of ordering upon binding of the rigid ligand 2, relative to binding of $\mathbf{1}$. The "snap shots" in the X-ray structure ${ }^{[13]}$ indicate that some degree of conformational freedom remains in the presence of the flexible ligand 1, so the results are consistent with a further decrease in protein flexibility upon binding of the rigid ligand.

We have previously probed the changes in Syk $\mathrm{tSH}_{2}$ structural dynamics upon binding to the flexible $\mathbf{1}$ in different protein segments by H/D exchange, proteolysis, and MALDI-MS. ${ }^{[14]}$ The results clearly showed that a major proportion of the decrease in H/D exchange upon binding could be attributed to the overall inter-SH2 linker region and its stabilization by hydrogen bonding. Figure 7 shows that the decreases in H/D exchange for the flexible and the rigid ligand are similar (the maximum mass deviation errors fall around $\pm 3 \mathrm{Da}$ ). The further reduction in protein dynamics and structural change upon binding of rigid 2, as indicated by the thermodynamic data, seems to be insensitive to the H/D exchange approach used here. It is conceivable that not every change in protein dynamics has equal sensitivity for H/D exchange (i.e., not all changes in structural dynamics are accompanied by large changes in hydrogen bonding). We assume that the structure of the interSH2 linker, the major site for H/D exchange, ${ }^{[14]}$ located far away from the ITAM binding site (Figure 1), is not much influenced by the flexibility of the ligand. In support of the global H/D exchange results, we also observed a change in charge state distribution upon ligand binding (Figure $6 \mathrm{~A} / \mathrm{B}$ ), which indicates a reduction in the overall protein dynamics upon binding. ${ }^{[30,39]}$

The kinetic analysis of the $\gamma$-ITAM-tSH2 interaction by SPR shows that the association and dissociation are extremely rapid, indicating a transient character of the bound state, with a short lifetime of approximately $4 \mathrm{~s}$. We propose a two-step binding mechanism in which the initial step is binding of one of the pY motifs of the ITAM to one of the $\mathrm{SH} 2$ domains (Scheme 2). Binding to the C-terminal SH2 domain is the likely initial step, as this $\mathrm{SH} 2$ domain has a much higher affinity for ITAMs than the $\mathrm{N}$-terminal $\mathrm{SH} 2 .{ }^{[25,40]}$ This initial binding step is then rapidly followed by binding to the $\mathrm{N}$-terminal $\mathrm{SH} 2$, which locks the $\mathrm{tSH} 2$ protein in a closed conformation, with reduced dynamics in the linker region (Scheme 2). Such a sequence of initial association followed by an intramolecular binding process in the complex has also been found to apply in other multivalent interactions. ${ }^{[22]}$ Our proposal is also based on the twostep kinetic model, which describes the experimental data well, especially at lower temperatures (Figure 8). It should be noted that this model is an approximation, as the second step also includes intramolecular binding, together with a conformational change to bring the reactants together. The second "intramolecular" step can be extremely rapid, as there is a high effective concentration due to the first binding step. Further- 


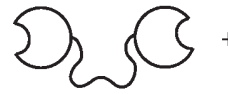

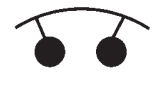

$B$

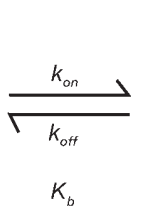

$K_{b}$

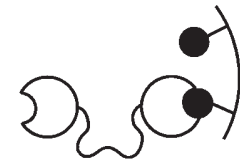

$A B 1$

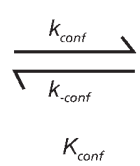

భ. ITAM$$
\text { }
$$

Syk $\mathrm{tSH}_{2}$

Scheme 2. Proposed mechanism for binding of diphosphorylated ITAM to Syk tSH2.

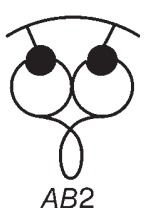

ing tools for further elucidation of the role of the Syk tSH2 inter$\mathrm{SH} 2$ distance in regulation of the kinase domain.

The two-step bivalent binding model we propose is compatible with the observed rapid dissociation kinetics in combination with high affinity. Fast kinetics are especially important for transient processes such as phosphorylation and dephosphorylation in

more, the proposed two-step model allows high affinity and rapid dissociation kinetics, in which high concentrations of competing peptide are necessary to prevent rebinding. ${ }^{[22,41]} \mathrm{Ac}-$ cording to the multivalent binding model of Huskens et al. ${ }^{[41]}$ the dissociation rate can approximate the rate for a corresponding monovalent system. This is in accordance with our

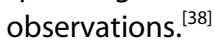

The sequential two-step model proposed here is different from the model proposed by Grucza et al. for binding of elTAM to Syk $\mathrm{tSH} 2 .{ }^{[26]}$ Their model includes an equilibrium between two distinct conformations in the unbound state. An important role in the model of Grucza et al. is attributed to the temperature dependence of $\Delta H^{\circ}$ for binding of the EITAM, as measured by calorimetry. From our van't Hoff analysis a linear temperature dependence of the observed $\Delta H^{0}$ is evident (Figure 3). In principle, a nonlinear temperature dependence of $\Delta H_{\text {obs }}^{0}$ could also be found for the model proposed by us if $K_{\text {conf }}$ is temperature-dependent [see Eq. (2b); Theory Section]. However, if $K_{\text {cont }}$ is $\gg 1$, Equation ( $2 \mathrm{~b}$ ) reduces to the sum of the contributions of the two steps $-\Delta H_{\text {obs }}^{0}=\Delta H_{\mathrm{b}}^{0}+\Delta H_{\text {conf }}^{0}$-as is expected when the $A B 2$ form is the major species at equilibrium. The van't Hoff analysis performed by us on the fluorescence data of Grucza et al. is also consistent with a constant $\Delta C_{p}$ with temperature (Table 1). Discrepancies between van't Hoff and calorimetric $\Delta H^{0}$ values have been observed and discussed before (references cited in Horn et al.). ${ }^{[42]}$ It must be concluded, even for complex binding models such as the binding of a molecule to a protein in conformation equilibrium, that $\Delta H^{0}$ values from calorimetry and van't Hoff analysis should not be different. ${ }^{[2]}$ With the SPR method used here we have indeed found good agreement between $\Delta H^{0}$ values from both methods. ${ }^{[38]}$

\section{Conclusion}

This study demonstrates that bivalent binding to Syk $\mathrm{tSH} 2$ has a marked effect on the $\mathrm{tSH} 2$ protein dynamics. In the unligated state, the protein is flexible, the origin of this flexibility largely residing in the helical coil connecting the two $\mathrm{SH} 2$ domains. This part of the $\mathrm{tSH} 2$ protein shows a high degree of $\mathrm{H} / \mathrm{D}$ exchange. ${ }^{[14]}$ This study makes it clear why rigid ITAM mimetics do not have the general entropic advantage of rigidization: the entropy price for fixing the flexible protein counteracts the entropy gain of rigidization of the ligand. On the other hand, ligands with rigid spacers of various lengths could be interest- signal-transduction pathways. Together with increased affinity and specificity, fast kinetics might also be relevant for the occurrence of multivalent interactions in nature.

\section{Theory Section}

The binding model explored in this study consists of two steps (see also Scheme 2): firstly an initial binding event, characterized by the equilibrium association constant $K_{\mathrm{b}}$, and secondly a change in the bound state, which may represent an intramolecular change in the complex, with binding of the second pY-motif to an $\mathrm{SH} 2$ domain, as shown in Scheme 2. The second step is characterized by the equilibrium constant $K_{\text {conf }}$ between the two bound states. $K_{\mathrm{b}}$ and $K_{\text {conf }}$ are given by Equation ( $1 \mathrm{a}$ )

$K_{b}=\frac{[A B 1]}{[A][B]}$

and Equation (1 b).

$K_{\text {conf }}=\frac{k_{\text {conf }}}{k_{- \text {conf }}}=\frac{[A B 2]}{[A B 1]}$

The observed equilibrium association constant $K_{\mathrm{obs}}$ is given by Equation (1 c)

$K_{o b s}=\frac{[A B 1]+[A B 2]}{[A][B]}$

and it can be derived [Eq. $(1 \mathrm{~d})]$ that:

$K_{\mathrm{obs}}=K_{\mathrm{b}}\left(1+K_{\text {conf }}\right)$

Application of the Gibbs-Helmholtz relationship [Eq. (2a)]

$\left[\frac{\partial(\ln K)}{\partial(T)}\right]_{p}=\frac{\Delta H^{0}}{R T^{2}}$

to Equation (1 d) allows it to be derived [Eq. ( 2 b)] that

$\Delta H_{\text {obs }}^{0}=\Delta H_{b}^{0}+\left(\frac{K_{\text {conf }}}{1+K_{\text {conf }}}\right) \Delta H_{\text {conf }}^{0}$

in which $\Delta H_{\mathrm{b}}^{0}$ and $\Delta H_{\text {conf }}^{0}$ are the enthalpy contributions of the binding step and the conformation change, respectively. The term $K_{\text {conf }} /\left(1+K_{\text {conf }}\right)$ equals the fraction of bound species in the $A B 2$ state.

For the proposed two-step model, the amount of bound protein at equilibrium as a function of ligand concentration will obey a onesite Langmuir binding isotherm (see also Figure 2). ${ }^{[43]}$ With the change in SPR signal $\left(R_{\text {eq }}\right)$ being proportional to the amount of 
bound protein, Equation (3) is obtained:

$R_{\mathrm{eq}}=\left(\frac{[B]}{[B]+K_{\mathrm{D}, \mathrm{obs}}}\right) R_{\max }$

in which $[\mathrm{B}]$ is the protein concentration (Syk $\mathrm{tSH} 2$ in this case) and $K_{\mathrm{D}, \mathrm{obs}}=1 / K_{\mathrm{obs}}$ with $K_{\mathrm{obs}}$ obeying Equation (1d when model 2 applies. $R_{\max }$ is the maximum binding capacity of the SPR sensor chip upon saturation of binding of all immobilized peptide.

\section{Experimental Section}

Syk tSH2 protein expression and purification: Fusion clones of the gluthathione S-transferase (GST) Syk tSH2 domain were kindly provided by Prof. Gabriel Waksman ${ }^{[13]}$ (Washington University, St. Louis, MI). The Escherichia coli strain BL21 contained the PGEX-KT vector with amino acids 10-273 of human Syk, enabling thrombin cleavage of the GST moiety. Isolation procedures were generally as previously described. ${ }^{[27]}$ The collected cellular protein fraction was purified on a GSTrap column (Amersham Pharmacia Biotech). Oncolumn cleavage with thrombin resulted in pure (>98\%) Syk tSH2, as determined by mass spectral analysis and SDS-PAGE. The protein concentration was determined by UV, with use of a molar extinction coefficient of 31630 at $280 \mathrm{~nm}$.

Synthesis of FceRI $\gamma$-ITAM-based Syk tSH2 ligands: The synthesis of the flexible all-peptide $\gamma$-ITAM 1 and the rigid ITAM-mimetic 2 was performed as previously described. ${ }^{[21]}$ For coupling to the SPR sensor the $\gamma$-ITAM was extended with an N-terminal 6-aminohexanoic acid $(A h x) .{ }^{[20]}$

SPR binding experiments: SPR experiments were performed with an IBIS II instrument (Eco Chemie, Utrecht, The Netherlands), essentially as previously described ${ }^{[44]}$ In brief, the Ahx-extended $\gamma$-ITAM peptide was covalently coupled to a Biacore CM5 sensor chip (Biacore $A B$, Uppsala, Sweden) through the free amino group by EDC/ NHS chemistry. The Ahx moiety was added to provide a spacer between the dextrane surface of the sensor chip and the binding peptide, to avoid steric hindrance upon binding of the $\mathrm{tSH} 2$ domain. Ahx- $\gamma$-ITAM-peptide $(2 \mathrm{mmol})$ in borate $(0.1 \mathrm{~m}) / \mathrm{NaCl}(1 \mathrm{~m})$ buffer $\mathrm{pH} 8.3$ was allowed to react over $10 \mathrm{~min}$. Experiments were performed in Hepes-buffered saline pH 7.4 (HBS-buffer) over a temperature range of 10 to $40^{\circ} \mathrm{C}$. The solutions were adjusted to temperature before injection to diminish temperature effects. The equilibrium constant of the protein for the coupled peptide $\left(K_{C}\right)$ was obtained by fitting with a Langmuir binding isotherm [Eq. (3); Theory Section]. Before fitting, a small correction of the free protein concentration for depletion due to binding to the sensor surface in the cuvette system was applied. ${ }^{[44]}$ The equilibrium constant in solution $\left(K_{\mathrm{S}}\right)$ was obtained from SPR competition experiments. The proteins, at a fixed concentration $(25 \mathrm{~nm})$, were mixed with the ligands $\mathbf{1}$ or $\mathbf{2}$ over a concentration range and the SPR equilibrium signal was assayed. $K_{\mathrm{s}}$ was obtained from fitting the inhibition curve as described. ${ }^{[23]}$

Thermodynamic analysis of equilibrium and transition state formation: The obtained $K_{\mathrm{S}}$ and $K_{\mathrm{c}}$ values (see above) over a range from 10 to $40^{\circ} \mathrm{C}$ were transformed into association binding constants $K_{\mathrm{A}}$ and plotted in a van't Hoff plot and fitted to the integrated van't Hoff equation [Eq. (4)].

$\ln K_{A}=\frac{-\Delta H^{0}\left(T^{0}\right)}{R T}+\frac{\Delta S^{0}\left(T^{0}\right)}{R}+\frac{\Delta C_{p}}{R}\left[\left(\frac{T-T^{0}}{T}\right)-\ln \left(\frac{T}{T^{0}}\right)\right]$
From this, the thermodynamic equilibrium parameters for binding $\Delta H^{0}$ and $\Delta S^{0}$ at reference temperature $T^{0}\left(25^{\circ} \mathrm{C}\right)$, and the heat capacity $\Delta C_{p}$ were derived.

According to transition state theory, kinetic data can be analyzed by use of the Eyring equation $K^{+}=k h / k_{\mathrm{B}} T$, in which $K^{+}$is the thermodynamic equilibrium constant for formation of the transition state, $k$ is the on- or off-rate constant, $h$ is Planck's constant, and $k_{\mathrm{B}}$ is Boltzmann's constant. For the linear Eyring plot of the dissociation kinetics, the activation parameters $\Delta H^{+}$and $\Delta S^{+}$are obtained from Equation (5)

$\ln \left(\frac{k_{\text {off }} \cdot h}{k_{B} \cdot T}\right)=-\frac{\Delta H^{\prime}=1}{R} \frac{1}{T}+\frac{\Delta S^{\prime}=}{R}$

For the nonlinear Eyring plot for association kinetics, $K^{+}$is treated in the same manner as for the equilibrium reaction, and fitted with Equation (4). ${ }^{[29]}$ From this fit the activation parameters $\Delta H^{+}$and $\Delta S^{\ddagger}$ at the reference temperature $\left(25^{\circ} \mathrm{C}\right)$, and $\Delta C_{p}^{\neq}$are obtained.

Assay of $\boldsymbol{k}_{\text {off }}$ rates: The $k_{\text {off }}$ rate of the Syk tSH2 domain from the sensor surface was assayed at temperatures over the range of 10 to $30^{\circ} \mathrm{C}$, essentially as described, ${ }^{[27]}$ with some adaptations for measurement at various temperatures. After equilibration of binding of Syk tSH2 protein $(100 \mathrm{~nm})$ at the desired temperature, mixing of the solution in the cuvette was stopped and $\gamma$-ITAM peptide $1(10 \mu \mathrm{L}, 1 \mathrm{~mm})$ or peptide Ac-pYETL-NH $\mathrm{NH}_{2}$ at an adjusted temperature was rapidly manually added. The dissociation phase was assayed with a high sampling rate of 5 data points per second. The SPR signal is very sensitive to temperature changes and this was sometimes visible as a linear baseline with a small positive or negative slope within $10 \mathrm{~s}$ after addition of the peptide. Correction for deviation of the baseline was performed by fitting the SPR signal in the dissociation phase $(R(t))$ with a monoexponential fit superposed on a baseline with slope $b$ as in Equation (6).

$R(t)=a+b t+c e^{-k_{\text {off }} t}$

The data points from the first second after addition of the competing peptide were discarded, as the signal is influenced by the bulk effect of mixing of the $1 \mathrm{~mm}$ peptide solution over this time interval. At least three experiments at each temperature were performed to obtain $k_{\text {off }}$. For temperatures above $30^{\circ} \mathrm{C}$ no $k_{\text {off }}$ values were determined, as the dissociation becomes very fast and the baseline becomes disturbed. For these temperatures $k_{\text {off }}$ was obtained by extrapolation of the Arrhenius plot.

Global kinetic analysis of the SPR signal: Kinetic analysis of the association phase was performed with the program CLAMP. ${ }^{[32]}$ Global analyses were performed by fitting several curves from different protein concentrations simultaneously, with use of a defined binding model. A diffusion step of the protein from bulk solution to the sensor surface was included $\left(k_{\mathrm{tr}}\right)$ in the binding models. To evaluate the robustness of the kinetic parameters returned by the fits, the Monte Carlo module of CLAMP was used. With this module 25 converged fits were performed with variation of the start parameters adjusted to $100 \%$. In these fits $R_{\max }$ and $k_{\text {off }}$ were kept at their independently determined experimental values.

H/D exchange and ESI-MS: Samples $(100 \mu \mathrm{m})$ of Syk tSH2, either ligand-free or bound to $\mathbf{1}$ or $\mathbf{2}$ (protein mixed with a threefold ligand excess), were diluted 20-times with ammonium acetate $\mathrm{D}_{2} \mathrm{O}$ (65 mM, neutral pD). This gives a final value of $95 \% \mathrm{D}_{2} \mathrm{O}$. Mass spectrometric measurements were performed on an LCT time-of-flight (ToF) mass spectrometer (Micromass) fitted with Z-electrospray source. Protein solutions (typically $100 \mu \mathrm{L}$ ) were infused into the 
LCT mass spectrometer at $2 \mu \mathrm{Lmin}^{-1}$ with a Harvard syringe pump. The ionization chamber of the mass spectrometer was flushed with $\mathrm{D}_{2} \mathrm{O}$ for a few minutes prior to analysis. Electrospray was achieved with a capillary voltage of $2500 \mathrm{~V}$. For mass calibration, an aqueous Csl solution was used ( $2 \mathrm{mg} \mathrm{mL}^{-1}$ in $50 \%$ isopropanol). In analysis of the noncovalent protein-peptide complex by ESI-MS, typical spectra would exclusively show the multiple charged ions corresponding to the molecular mass of the noncovalent Syk-ITAM complex. In order to analyze the deuterium incorporation in the protein, high cone voltages of $190 \mathrm{~V}$ were used to disrupt the protein-peptide complex, to obtain the fragment ions corresponding to the intact protein. The same cone voltage of $190 \mathrm{~V}$ was applied when spraying the ligand-free protein in order to keep experimental conditions identical. Alternatively, the mass of the deuterated protein can be obtained by subtracting the mass of the fully deuterated peptide from the mass of the deuterated protein-peptide complex. ${ }^{[14]}$ The total number of exchangeable hydrogens of Syk $\mathrm{tSH} 2$ was calculated from its amino acid sequence, being 465.5 out of a total of 490 in $95 \% \mathrm{D}_{2} \mathrm{O}$. Protein masses were analyzed by ESI-MS; the combined data from several charge states of the protein in each spectrum were used to calculate the molecular mass.

To determine the molecular mass of the originally nondeuterated protein, solutions ( $5 \mu \mathrm{m}$ in $50 \%$ acetonitrile/ $1 \%$ formic acid) were analyzed. The experimental molecular mass of the Syk tSH2 domain was $29788( \pm 1) \mathrm{Da}$, in agreement with the calculated mass of $29787.95 \mathrm{Da}$.

Keywords: kinetics . multivalent interactions phosphopeptides $\cdot$ protein dynamics $\cdot$ thermodynamics

[1] J. Kuriyan, D. Cowburn, Annu. Rev. Biophys. Biomol. Struct. 1997, 26, 259.

[2] S. E. Shoelson, Curr. Opin. Chem. Biol. 1997, 1, 227.

[3] C. S. Navara, Curr. Pharm. Des. 2004, 10, 1739.

[4] B. D. Gomperts, Y. Churcher, A. Koffer, T. H. Lillie, P. E. Tatham, T. D. Whalley, Int. Arch. Allergy Appl. Immunol. 1991, 94, 38.

[5] H. Turner, J. P. Kinet, Nature 1999, 402, B24.

[6] V. Rolli, M. Gallwitz, T. Wossning, A. Flemming, W. W. Schamel, C. Zurn, M. Reth, Mol. Cell 2002, 10, 1057.

[7] J. Zhang, M. L. Billingsley, R. L. Kincaid, R. P. Siraganian, J. Biol. Chem. 2000, 275, 35442.

[8] S. Atwell, J. M. Adams, J. Badger, M. D. Buchanan, I. K. Feil, K. J. Froning, X. Gao, J. Hendle, K. Keegan, B. C. Leon, H. J. Muller-Dieckmann, V. L. Nienaber, B. W. Noland, K. Post, K. R. Rajashankar, A. Ramos, M. Russell, S. K. Burley, S. G. Buchanan, J. Biol. Chem. 2004, 279, 55827.

[9] S. Latour, J. Zhang, R. P. Siraganian, A. Veillette, Embo J. 1998, 17, 2584

[10] S. Kumaran, R. A. Grucza, G. Waksman, Proc. Natl. Acad. Sci. USA 2003, $100,14828$.

[11] M. H. Hatada, X. Lu, E. R. Laird, J. Green, J. P. Morgenstern, M. Lou, C. S. Marr, T. B. Phillips, M. K. Ram, K. Theriault, et al., Nature 1995, 377, 32.

[12] R. H. Folmer, S. Geschwindner, Y. Xue, Biochemistry 2002, 41, 14176.

[13] K. Futterer, J. Wong, R. A. Grucza, A. C. Chan, G. Waksman, J. Mol. Biol. 1998, 281, 523

[14] M. I. Catalina, M. J. E. Fischer, F. J. Dekker, R. M. J. Liskamp, A. J. R. Heck, J. Am. Soc. Mass Spectrom. 2005, 16, 1039.
[15] L. M. Keshvara, C. Isaacson, M. L. Harrison, R. L. Geahlen, J. Biol. Chem. 1997, 272, 10377.

[16] P. J. Barnes, Nature 1999, 402, B31.

[17] J. M. Oliver, C. L. Kepley, E. Ortega, B. S. Wilson, Immunopharmacology 2000, 48, 269.

[18] W. S. Wong, K. P. Leong, Biochim. Biophys. Acta 2004, 1697, 53.

[19] R. Ruijtenbeek, J. A. Kruijtzer, W. van de Wiel, M. J. E. Fischer, M. Fluck, F. A. M. Redegeld, R. M. J. Liskamp, F. P. Nijkamp, ChemBioChem 2001, 2, 171.

[20] F. J. Dekker, N. J. de Mol, J. van Ameijde, M. J. E. Fischer, R. Ruijtenbeek, F. A. M. Redegeld, R. M. J. Liskamp, ChemBioChem 2002, 3, 238.

[21] F. J. Dekker, N. J. de Mol, M. J. E. Fischer, R. M. J. Liskamp, Bioorg. Med. Chem. Lett. 2003, 13, 1241.

[22] J. Rao, J. Lahiri, R. M. Weis, G. M. Whitesides, J. Am. Chem. Soc. 2000, $122,2698$.

[23] N. J. de Mol, M. B. Gillies, M. J. E. Fischer, Bioorg. Med. Chem. 2002, 10, 1477.

[24] E. A. Ottinger, M. C. Botfield, S. E. Shoelson, J. Biol. Chem. 1998, 273, 729.

[25] T. Chen, B. Repetto, R. Chizzonite, C. Pullar, C. Burghardt, E. Dharm, Z. Zhao, R. Carroll, P. Nunes, M. Basu, W. Danho, M. Visnick, J. Kochan, D. Waugh, A. M. Gilfillan, J. Biol. Chem. 1996, 271, 25308.

[26] R. A. Grucza, K. Futterer, A. C. Chan, G. Waksman, Biochemistry 1999, 38, 5024.

[27] N. J. de Mol, M. I. Catalina, M. J. E. Fischer, I. Broutin, C. S. Maier, A. J. R. Heck, Biochim. Biophys. Acta 2004, 1700, 53.

[28] J. R. Faeder, W. S. Hlavacek, I. Reischl, M. L. Blinov, H. Metzger, A. Redondo, C. Wofsy, B. Goldstein, J. Immunol. 2003, 170, 3769.

[29] B. L. Chen, W. A. Baase, J. A. Schellman, Biochemistry 1989, 28, 691.

[30] X. Yan, J. Watson, P. S. Ho, M. L. Deinzer, Mol. Cell. Proteomics 2004, 3, 10.

[31] A. Miranker, C. V. Robinson, S. E. Radford, R. T. Aplin, C. M. Dobson, Science 1993, 262, 896.

[32] T. A. Morton, D. G. Myszka, Methods Enzymol. 1998, 295, 268.

[33] J. R. Engen, W. H. Gmeiner, T. E. Smithgall, D. L. Smith, Biochemistry $1999,38,8926$.

[34] M. Y. Kim, C. S. Maier, D. J. Reed, M. L. Deinzer, Protein Sci. 2002, 11, 1320.

[35] R. Anderegg, D. Wagner, J. Am. Chem. Soc. 1995, 117, 1374.

[36] P. Schuck, Biophys. J. 1996, 70, 1230.

[37] Y. S. Day, C. L. Baird, R. L. Rich, D. G. Myszka, Protein Sci. 2002, 11, 1017.

[38] N. J. de Mol, F. J. Dekker, I. Broutin, M. J. E. Fischer, R. M. J. Liskamp, J. Med. Chem. 2005, 48, 753.

[39] A. Mohimen, A. Dobo, J. K. Hoerner, I. A. Kaltashov, Anal. Chem. 2003, $75,4139$.

[40] S. S. Narula, R. W. Yuan, S. E. Adams, O. M. Green, J. Green, T. B. Philips, L. D. Zydowsky, M. C. Botfield, M. Hatada, E. R. Laird, et al., Structure 1995, 3, 1061.

[41] J. Huskens, A. Mulder, T. Auletta, C. A. Nijhuis, M. J. Ludden, D. N. Reinhoudt, J. Am. Chem. Soc. 2004, 126, 6784.

[42] J. R. Horn, D. Russell, E. A. Lewis, K. P. Murphy, Biochemistry 2001, 40, 1774

[43] D. A. Lauffenburger, J. J. Linderman, Receptors: Models for Binding, Trafficking, and Signalling, Oxford University Press, Oxford, 1993.

[44] N. J. de Mol, E. Plomp, M. J. E. Fischer, R. Ruijtenbeek, Anal. Biochem. 2000, 279, 61

Received: April 5, 2005

Published online on October 27, 2005 